\title{
Application of U-FAST Technology in Sintering of Titanium Biomaterials
}

\author{
Katarzyna Jach ${ }^{1 *}$, Paweł Figiel ${ }^{2}$ and Anna Biedunkiewicz ${ }^{2}$ \\ ${ }^{1}$ GeniCore Sp. z o.o., Wolczyńska 133, 01-919 Warsaw, Poland \\ ${ }^{2}$ Faculty of Mechanical Engineering and Mechatronics, Institute of Materials Science and Engineering, Poland \\ *Corresponding author: Katarzyna Jach, GeniCore Sp. z o.o., Wolczyńska 133, 01-919 Warsaw, Poland
}

\begin{tabular}{lll}
\hline ARTICLE INFO & & ABSTRACT \\
Received: & & Citation: Katarzyna Jach, Paweł Figiel, Anna Biedunkiewicz. Application of U-FAST \\
Published: 26,2019 & & Technology in Sintering of Titanium Biomaterials. Biomed J Sci \& Tech Res 23(5)-2019. \\
& BJSTR. MS.ID.003952.
\end{tabular}

\section{Short Communication}

The titanium has been a part of the group of materials used in areas where excellent corrosion resistance and high strength are required. Due to its outstanding properties it is used in medicine, mainly thanks to biocompatibility and corrosion resistance in the environment of body fluids. It is used to make implants, stents and prostheses. Nevertheless, the titanium main disadvantage, apart from high manufacturing costs, is its relatively low wear resistance. The titanium metal matrix composites (TMMCs) are increasingly used to eliminate this disadvantage. Hard ceramic reinforcement phases in the form of fiber or powders, e.g. $\mathrm{SiC}, \mathrm{TiC}, \mathrm{Al}_{2} \mathrm{O}_{3}, \mathrm{TiB}_{2}$, are often added to the metallic titanium matrix for this purpose [1-7]. The preliminary studies of titanium composites reinforced with nanocrystalline powders from $(\mathrm{Ti}, \mathrm{Mo}) \mathrm{C} / \mathrm{C}$ system are presented by this paper.

The powders were sintered using an SPS-type furnace (U-FAST, GeniCore, Poland). Recent years have showed significant developments in the methods of sintering by activated electric field. These methods allow to perform the sintering process in a very short period of time from a few to several minutes, thus reducing the unfavorable grain growth in the consolidated material. In these techniques the sintering process is performed at a uniaxial pressure. U-FAST (Upgraded Field Assisted Sintering Technology) having a characteristic method of powder heating. The innovative solutions open the perspective for sintering of the new materials and has unique characteristics. Pulse power modular supplies offer the shortest impulse duration, less than $1 \mathrm{~ms}$. Together with the higher power supply voltage $(14 \mathrm{~V})$, they make this technology effective, energy-saving and dedicated to the consolidation of nanocrystalline materials $[8,9]$.

\section{Experimental}

As starting matrix material, the one type of cp-Ti powder (grade 1), with a spherical shape and its average particle size around 100 $\mu \mathrm{m}$ from SLM Solutions $\mathrm{GmbH}$, was employed. As a reinforcements two type of nanoparticles were used: (Ti,Mo)C with an average crystallite size of $25 \mathrm{~nm}$ and (Ti,Mo)C/C carbides embedded in carbon network with an average crystallite size of $12 \mathrm{~nm}$ and ca 40 wt.\% elemental carbon. Before the sintering titanium with reinforcing carbides phase was milled during $12 \mathrm{~h}$, in order to obtain a uniform mixing of powders. Sintering processes were conducted in high vacuum $\left(10^{-5}\right.$ mbar $)$. Powder mixtures were placed into cylindrical graphite die with inner diameter of $20 \mathrm{~mm}$.

The pulse sequence was set to $1: 1\left(\mathrm{t}_{\mathrm{ON}}: \mathrm{t}_{\mathrm{OFF}}\right)$. The temperature was monitored by an axial and a side optical pyrometer. Samples were heated to the desired temperatures with the ramp of $400^{\circ} \mathrm{C} /$ min. Sintering temperature was $1050^{\circ} \mathrm{C}$ and $1150^{\circ} \mathrm{C}$ with 2 min and 24 min of dwell time, respectively. In all cases, the U-FAST was performer under uniaxial mechanical pressure of $50 \mathrm{MPa}$, applied during the whole sintering process, including heating ramps and cooling. The density was determined by hydrostatic method after ultrasonic cleaning and vacuum drying. The microhardness was measured by Vickers method under load 100 g. Potentiodynamic polarization measurements were carried out on the Atlas-Sollich 9833 potentiostat in a three-electrode system. The parameters of the test were as follows: a scan rate of $0.01 \mathrm{~V} / \mathrm{s}$ at a potential 
initiated at $-1.2 \mathrm{~V}$ to $+2.0 \mathrm{~V}$. The calomel (reference) and graphite (auxiliary) electrodes were used. The analysis of the results has been carried out by means of the AtlasLab software. Pure titanium (cp-Ti) and Ti-6Al-4V alloy were used as reference samples.

\section{Results}

The sintering processes of titanium materials with the addition of titanium strengthening phases ( $\mathrm{Ti}, \mathrm{Mo}) \mathrm{C}$ and $(\mathrm{Ti}, \mathrm{Mo}) \mathrm{C} / \mathrm{C}$ were carried out. The materials were sintered at $1050^{\circ} \mathrm{C}$, which allowed to obtain a density of samples corresponding to theoretical values.
In the case of addition $20 \%(\mathrm{Ti}, \mathrm{Mo}) \mathrm{C} / \mathrm{C}$ the minimum temperature to achieve total compaction was $1150^{\circ} \mathrm{C}$ with dwell time $24 \mathrm{~min}$. The density after sintering at $1050 \mathrm{oC}$ was $3.86 \mathrm{~g} / \mathrm{cm}^{3}$, thus not been studied. The obtained values are summarized in Table 1. Vickers hardness measurements made at different locations on the surface of each samples are summarized in Figure 1. The samples were polished to a mirror finish before the hardness measurement. The measured hardness was observed to be near uniform throughout each sintered sample, indicating uniform densification (Figure 1). Based on images from an optical microscope (OM), the microstructure of the tested materials was determined.

Table 1: Density of titanium-based materials.

\begin{tabular}{|c|c|c|c|c|c|c|}
\hline Material & cp-Ti & Ti-6Al-4V & Ti+10wt.\% (Ti,Mo)C & Ti+20wt.\% (Ti,Mo)C & $\mathrm{Ti}+10$ wt. $\%(\mathrm{Ti}, \mathrm{Mo}) \mathrm{C} / \mathrm{C}$ & $\mathrm{Ti}+20$ wt. $\%(\mathrm{Ti}, \mathrm{Mo}) \mathrm{C} / \mathrm{C}$ \\
\hline Density, $\mathrm{g} / \mathrm{cm}^{3}$ & 4.50 & 4.46 & 4.66 & 4.70 & 4.65 & 4.72 \\
\hline
\end{tabular}

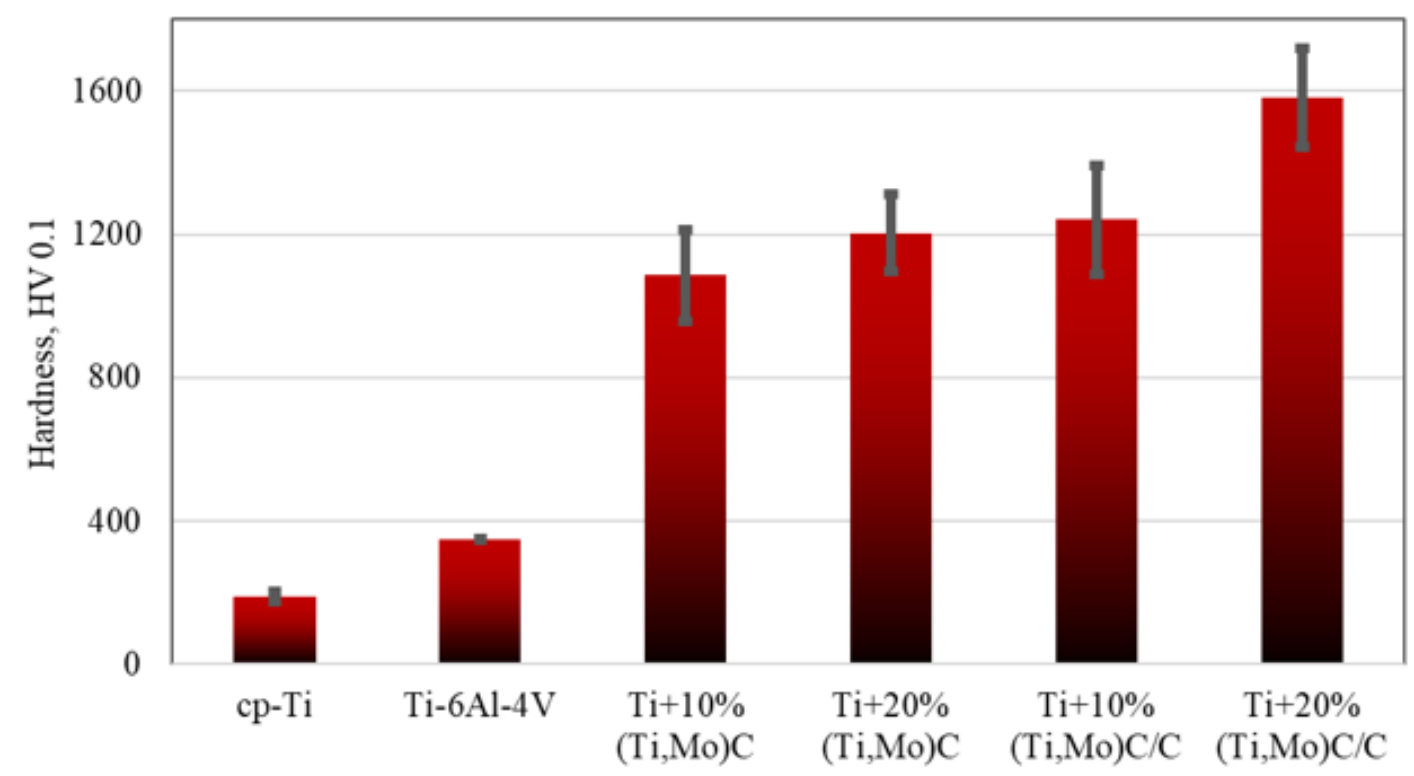

Figure 1: Microhardness measurements of manufactured materials.

Pictures are shown in Figure 2. In the case of pure titanium, a typical needle (dendritic) structure is visible (Figure 2a). For the Ti-6Al-4V alloy (Figure 2b), the bi-modal microstructure of titanium $\alpha$ and $\beta$ is observe. The lighter fields are the $\alpha$ phase, while the darker fields are the Widmanstätten phase. Figures 2c-f show the microstructure of composites with a strengthening phase. The greater addition of this phase has a positive effect on the homogeneity of the material, which is confirmed by measurements of both density and hardness. Smaller amounts of matrix are visible

Table 2: Corrosion parameters of sintered materials- Ringer solution. in the case of (Ti,Mo)C/C type of carbides, due to the reaction of free carbon with the titanium matrix. This is especially visible in the case of 20\% (Ti,Mo)C/C (Figures 2 \& 3) (Table 2). For selected materials tested corrosion. Polarizing curves for titanium and titanium composites are shown in Figure 3. Corrosion tests were carried out in Ringer's solution, an electrolyte with a composition similar to extracellular fluid, simulating body fluids. Corrosion parameters of sintered materials are shown in Table 2.

\begin{tabular}{|c|c|c|c|c|c|}
\hline Material & cp-Ti & Ti-6Al-4V & Ti+20wt.\% (Ti,Mo)C & Ti+10wt.\% (Ti,Mo)C/C & Ti+20wt\% (Ti,Mo)C/C \\
\hline Corrosion potential $\mathrm{E}_{\text {corr }}, \mathrm{V}$ & -0.328 & -0.392 & -0.427 & -0.643 & -0.498 \\
\hline Corrosive current $\mathrm{I}_{\text {corr }}, \mathrm{A} / \mathrm{cm}^{2}$ & $2.1 \cdot 10-6$ & $2.3 \cdot 10^{-6}$ & $6.28 \cdot 10^{-6}$ & $8.26 \cdot 10^{-6}$ & $10.37 \cdot 10^{-6}$ \\
\hline
\end{tabular}




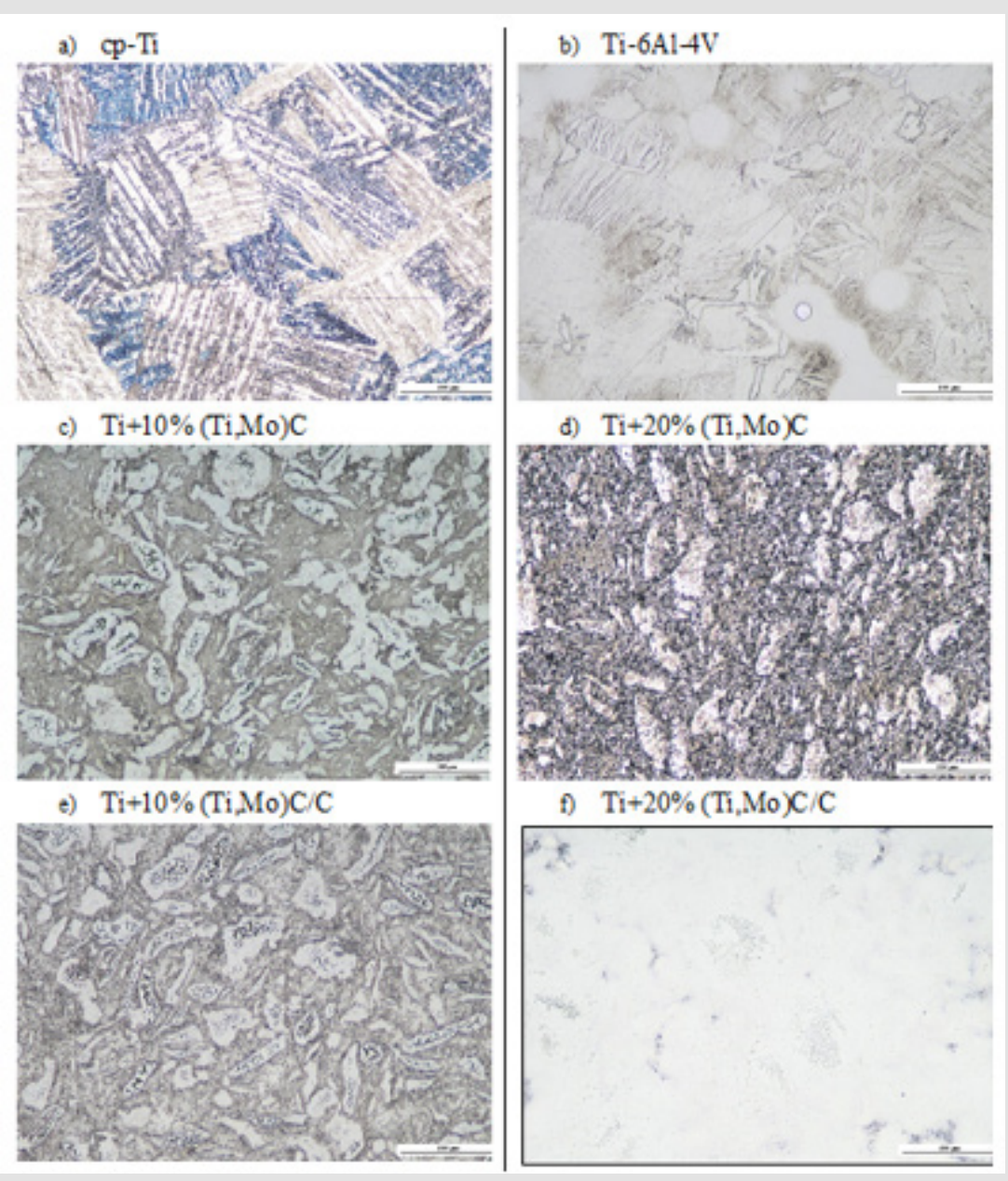

Figure 2: The microstructure of sintered materials. The scale shown in the images is 100 microns.

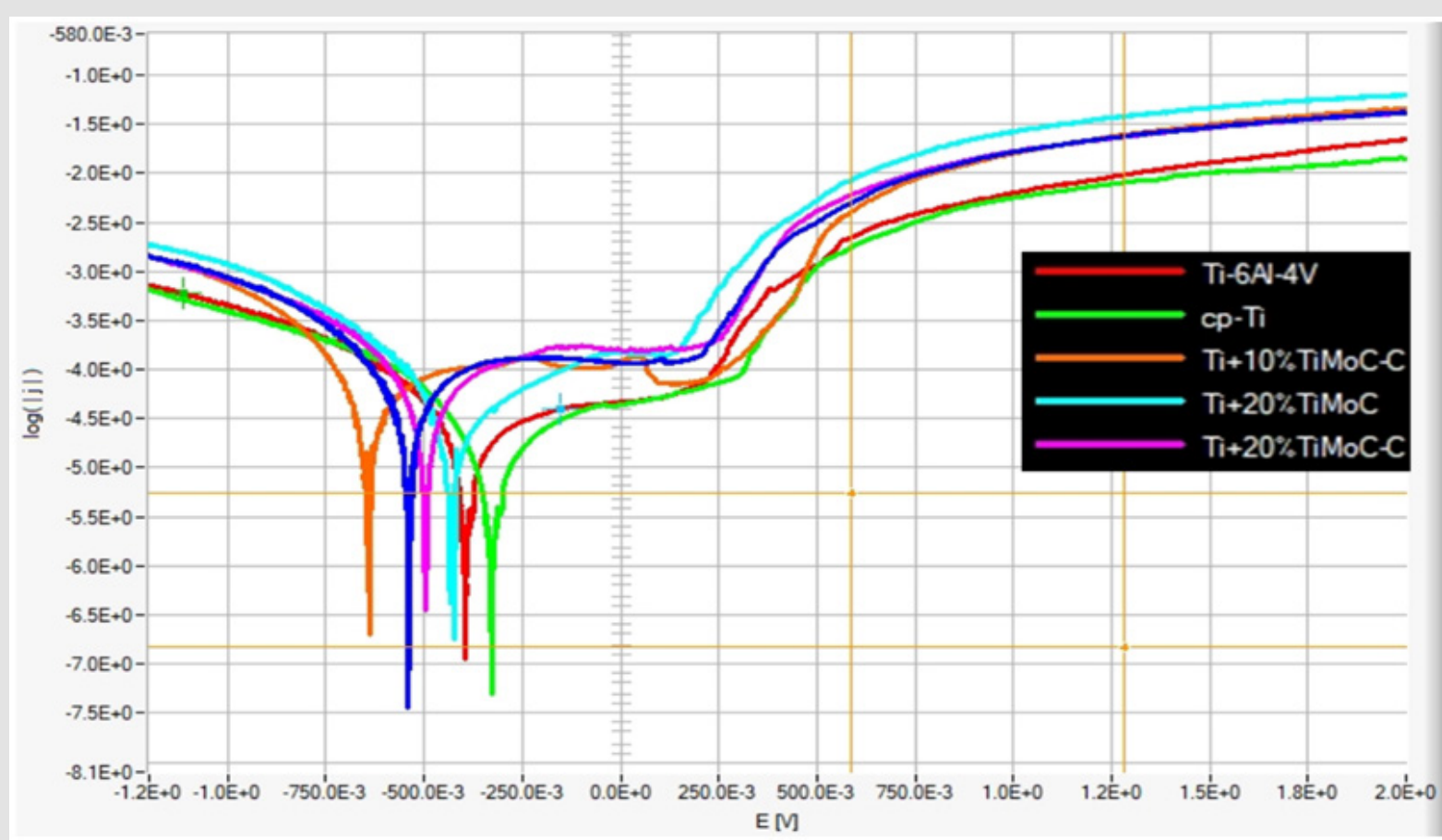

Figure 3: Polarization curves of titanium and titanium-based materials in Ringer's solution. 
In case of pure Ti sample immersed in artificial saliva solution, corrosion potential was at the level of $-0.328 \mathrm{~V}$ and corrosion current density reached $2.1 \cdot 10^{-6} \mathrm{~A} \cdot \mathrm{cm}^{-2}$, and in the case of Ti- $6 \mathrm{Al}-4 \mathrm{~V}$ alloy corrosion potential was at the level of $-0.392 \mathrm{~V}$ and corrosion current density reached $2.3 \cdot 10^{-6} \mathrm{~A} \cdot \mathrm{cm}^{-2}$ Corrosion results shows that the composites generally displayed similar polarization curves and passivity characteristics. However, the corrosion potentials $\left(\mathrm{E}_{\text {corr }}\right)$ of the composites were clearly distinct and occurred in the ranges of -0.498 to $-0.643 \mathrm{~V}$. Analysis of the results of corrosion tests showed that the corrosion potential $\left(\mathrm{E}_{\text {corr }}\right)$ and the density of corrosive current $\left(\mathrm{I}_{\text {corr }}\right)$ of composites show a constant tendency to change the value with the increase of the mass fraction of the reinforcement phase. When titanium composites were immersed in Ringer's solution, the corrosion potential generally shifts to lower values towards cathodic region. Also, corrosion current increased with increasing reinforcing phase content.

\section{Summary}

Powder contaminations are an obstacle to mass transport processes during the sintering. U-FAST technology allows better control over diffusion processes. Spark discharges generated during sintering remove adsorbed gases and oxides from the surface of particles, facilitating the formation of active contacts between sintered powder particles. This affects the lower sintering temperature and a shorter heating time. This work has already produced perfectly concentrated $(100 \%$ of theoretical density) titanium material, a popular alloy as well as titanium composite materials at $1050^{\circ} \mathrm{C}$ by $2 \mathrm{~min}$. Together with the applied load, it results in rearrangement of powder particles and obtaining a homogeneous sintered microstructure.

The use of 20 wt.\% (Ti,Mo)C additive in U-FAST sintering technology allowed to obtain materials with the HV hardness

\section{ISSN: 2574-1241}

DOI: 10.26717/BJSTR.2019.23.003952

Katarzyna Jach. Biomed J Sci \& Tech Res

cC) This work is licensed under Creative

Submission Link: https://biomedres.us/submit-manuscript.php
$1203 \pm 108$, even up to $600 \%$ compared to pure titanium. In the case of $20 \mathrm{wt} . \%$ of the (Ti,Mo)C/C additive, the material has a hardness of $1581 \pm 138 \mathrm{HV}$, which is over $800 \%$ higher than hardness of the pure titanium. Corrosion properties of titanium composites similar to reference cp-Ti and Ti-6Al-4V were obtained. The article shows that U-FAST technology is useful for the production of titanium-based biomaterials. Further optimization of the powders preparation and sintering processes will contribute to the manufacturing materials with even more favorable parameters.

\section{References}

1. C Poletti, M Balog, T Schubert, V Liedtke, C Edtmaier (2008) Production of titanium matrix composites reinforced with $\mathrm{SiC}$ particles. Compos Sci Technol 68(9): 2171-2177.

2. DE Alman, JA Hawk (1999) The abrasive wear of sintered titanium matrix-ceramic particle reinforced composites. Wear 225-229(1): 629639.

3. HO Gülsoy, V Gunay, T Baykara (2015) Influence of TiC, TiN and TiC(N) additions on sintering and mechanical properties of injection moulded titanium-based metal matrix composites. Powder Metall 58(1): 30-35.

4. AAM da Silva, A Meyer, JF dos Santos, CEF Kwietniewski, TR Strohaecker (2004) Mechanical and metallurgical properties of friction-welded TiC particulate reinforced Ti-6Al-4V. Compos Sci Technol 64(10-11): 14951501.

5. D Gu, YC Hagedorn, W Meiners, K Wissenbach, R Poprawe (2011) Nanocrystalline TiC reinforced Ti matrix bulk-form nanocomposites by Selective Laser Melting (SLM): Densification, growth mechanism and wear behavior. Compos Sci Technol 71(13): 1612-1620.

6. P Figiel, D Garbiec, A Biedunkiewicz, W Biedunkiewicz, P Kochmański, et al. (2018) Microstructural, Corrosion and Abrasive Characteristics of Titanium Matrix Composites. Arch Metall Mater 63(4): 2051-2059.

7. Z Wang, H Zhang, C Guo, W Liu, Z Yang, et al. (2016) J Mater Sci 51(10): 4996-5007.

8. K Jach, M Rosiński (2018) Ceramic Materials 70(4): 293-300.

9. GeniCore

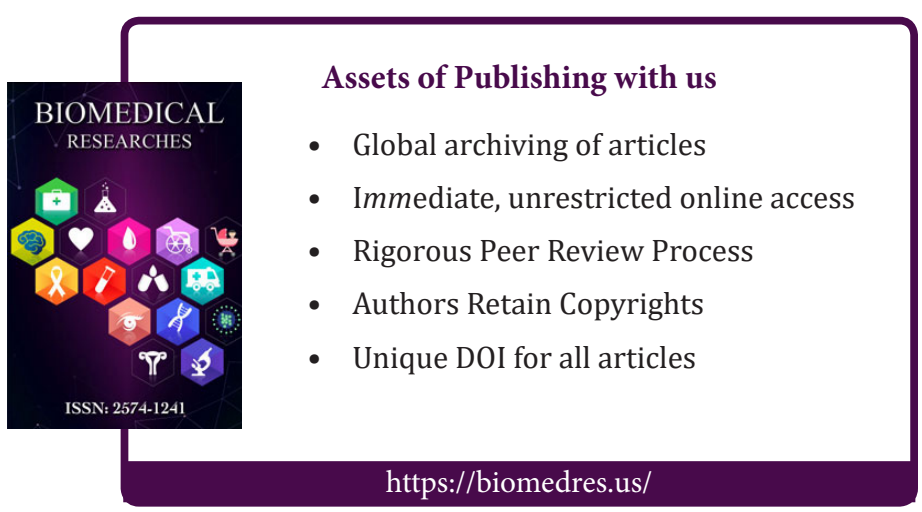

Copyright@ Katarzyna Jach | Biomed J Sci \& Tech Res | BJSTR. MS.ID.003952. 